\title{
Allowing One's Own Bodily Experience to "Count": Elaborating on Inter-subjectivity and Subjectivity in Phenomenological Studies
}

\author{
Karen Synne Groven ${ }^{\mathrm{a} *}$ and Gunn Engelsrud ${ }^{\mathrm{b}}$ \\ ${ }^{a} \&^{b}$ Institute of Health and Society, University of Oslo, Oslo, Norway \\ ${ }^{b}$ Department of Physical Education, Norwegian School of Sports Science, Oslo, \\ Norway
}

\begin{abstract}
Phenomenology, according to Heidegger and Merleau-Ponty, looks at human beings in the world. Drawing on their perspective, one could argue that intersubjectivity, like a researcher's subjectivity, should be explicitly acknowledged in phenomenological studies. In the following pages we explore how using this approach can make findings more transparent and trustworthy. This study is based on a review of five articles focused on subjectivity and inter-subjectivity in phenomenological studies. In addition, we draw on the first author's experiences as a $\mathrm{PhD}$ candidate studying to become a "phenomenological" researcher.

Our findings reveal that reflecting explicitly on bodily subjectivity during the research process can reveal connections between the context of the interview, how the material is created socially and textually and how the researcher utilized information from her own body in the interpretation of the material. This, in turn, is likely to make the findings more inter-subjective and transparent, and thus more trustworthy and valid. Our findings point to the value of letting one's own bodily experiences "count" in the process of determining how to explore the phenomena in question. Although the literature offers guidelines, each project and each researcher is unique. In this light, personal reflections are likely to highlight the value of critically engaging - and making explicit - the researcher's own experiences, both during and after the interview process.
\end{abstract}

Keywords: phenomenology, inter-subjectivity, bodily experience, reflection

\section{Introduction}

Questions regarding subjectivity and inter-subjectivity are fundamental in science and philosophy (Zahavi, 2008; Neumann \& Neumann, 2011). In qualitative research, which is based on encounters between people, the question of how scholars critically engage their own subjectivity during the research process is considered crucial to determining the integrity, trustworthiness and validity of their findings (Finlay, 2011; 
Todres, 2001; Engelsrud, 2005; Neumann \& Neumann, 2011). This process, however, should be explicitly acknowledged, since a researcher's subjectivity is dependent upon, and actualized as, an inter-subjective relationship with others (Prætorisus, 2003; Finlay, 2011).

In this article, we will investigate how subjectivity and inter-subjectivity are expressed and dealt with in five research texts. Since a good deal of qualitative research explores this subject, we have chosen to limit our investigation to texts that explicitly incorporate phenomenology. Finding the balance between subjectivity and intersubjectivity is considered challenging, particularly for phenomenological researchers. Due to conflicting views on these issues, phenomenological researchers are often criticized for bringing their own pre-conceptions into the research process (Dahlberg, Raaheim, \& Gjengedahl, 2011). The risk of this type of criticism can be seen in relation to phenomenological ideas concerning "bracketing." Husserl, in his descriptions of phenomenological reduction, argued that researchers should "bracket," or parenthesize their pre-conceptions, including their common sense and prior scientific knowledge. In other words, researchers should temporarily set aside their assumptions and theories to ensure that they will explore the phenomenon under consideration in an open and unprejudiced manner (Dahlberg et al., 2008; Cerbone, 2012).

Heidegger and Merleau-Ponty, however, argue that phenomenology considers the experiences of human beings in and of the world (Merleau-Ponty, 2002; Heidegger, 1998; Dahlberg, 2011), not in isolation. Heidegger's concept of "being-in-theworld" and Merleau-Ponty's emphasis on how the world is flesh both privilege intersubjectivity as a primordial quality of the human experience (Dahlberg, 2011; Käll, 2006). This implies that inter-subjectivity, like the researcher's subjectivity, should be regarded as an essential part of the research process.

In this article, we will explore ways in which inter-subjectivity can be acknowledged and reflected upon in phenomenological studies. More precisely, we will highlight how findings in a selection of research papers can be seen as emerging out of the researcher-participant relationship, given that the researchers reflect on their own experiences as well as those of the participants. At the same time, we acknowledge that establishing a balance between inter-subjective concerns and the researcher's wish to achieve the study aims is likely to affect this process.

\section{Reviewing Inter-subjective Dimensions: Five Cases}

We will begin examining these issues by reviewing five empirical and methodological articles that were influenced in various ways by the writings of Merleau-Ponty and also acknowledge their inspiration in phenomenology as a methodological tradition. These articles share an explicit focus on the role of the researcher as a co-producer of knowledge. They differ, however, in their focus and scope, and offer divergent arguments concerning subjectivity and inter-subjectivity arguments that might be of particular relevance for noise researchers.

As a means of categorizing these articles, we have chosen different headings that hopefully reflect the main points of argument related to our research focus. Additionally, we will elaborate on our own experiences as researchers inspired by 
phenomenology. In particular, we will draw on the first author's experiences as a $\mathrm{PhD}$ student employing inter-subjectivity and her own pre-conceptions to develop new and intriguing findings.

\section{Reflexivity as a Means of Acknowledging Subjectivity}

Linda Finlay is a phenomenological researcher who advocates including and highlighting research subjectivity during the entire research process. She has written several articles dealing with methodology, based on a phenomenological approach. We are greatly inspired by her work, but also critical of some of her arguments.

We will begin our review by focusing on one of her most frequently cited articles, "Quoting the researcher: The provenance, process, and practice of reflexivity" (2002). In this article, Finlay calls attention to the role of the researcher in producing the empirical material, and the need to include one's subjectivity throughout the research process. According to Finlay, several difficulties are likely to arise in this effort. In particular, she points to the researcher's risk of becoming too personal or too subjective at the expense of research distance from the participants she is interviewing. In addition, she notes that involving oneself can make the researcher vulnerable and subject to criticism from other researchers. Finlay's main emphasis in this article is on the importance of the researcher's reflection in increasing what she terms the "integrity and trustworthiness of phenomenological research" (Finlay, 2002, p. 531). In this context, she introduces her own definition of reflexivity, describing it as an approach through which the researcher engages in "explicit, self-aware analysis of the research process. Through the use of reflexivity, subjectivity in research can be transformed from a problem to an opportunity" (Finlay, 2002, p. 531).

Reflexive analysis encompasses continual evaluation of subjective responses, inter-subjective dynamics, and the research process itself. Finlay argues for a shift in the understanding of data collection, from being regarded as an objective undertaking accomplished through detailed scrutiny to a process in which the researcher is recognized as an active constructor of data and knowledge. In presenting her position, Finlay acknowledges that she was inspired by the work of ethnographers:

The reflexive ethnographer does not simply report facts or truths, but actively constructs interpretations of his or her experiences in the field and then questions how those interpretations came about. (Finlay, 2002, p. 532)

Finlay asserts that reflexivity is not equivalent of reflection, but at the same time emphasizes their similarities. She places them on a continuum where both ends are acknowledged to be equally important as a means of engaging one's own subjectivity. At one end of the scale, to paraphrase Finlay, reflection can be understood as "thinking about" (Finlay, 2002, p. 532). In other words, the researcher looks at the phenomenon under scrutiny from a certain distance, usually after the event actually takes place. Finlay places reflexivity at the other end of the scale, emphasizing how it involves a more immediate, continuing and subjective self-awareness (Finlay, 2002). The terms are not clearly distinguished from each other, which might indicate that Finlay sees them as intertwined. In the second article discussed here, Finlay offers additional thoughts on researcher subjectivity. 


\section{Bodily Inter-subjectivity during the Interview Process}

The second article we will consider is also by Finlay. In "The body's disclosure in phenomenological research," she discusses the significance of acknowledging bodily inter-subjectivity during the interview process. Her starting point is the tendency of phenomenological researchers to shift their attention to the written transcripts once the interview is conducted and transcribed. Consequently, the researcher is likely to restrict herself to an analysis of de-contextualized words rather than reflect on the interview process itself. As a result, Finlay argues, the researcher runs the risk of missing bodily signals and gestures that could influence the findings. She argues, "If embodiment is a pervasive fundamental presence in the lifeworld, it surely behooves phenomenological researchers to engage with it in a serious and sustained way" (Finlay, 2008, p. 20).

Finlay's line of thought here draws heavily on the writings of Merleau-Ponty. Central to his writing on phenomenology is a view of the body as lived and intentional, inherent in the world. The body is regarded as fundamental in and to all human experience, and being a body subject means already being in-the-world (Merleau-Ponty, 2002). Merleau-Ponty also emphasizes that consciousness is never an isolated process located in a person's brain. Rather, it is embodied, so that body and self, as well as body and world, are intertwined. Inspired by this perspective, Finlay argues that the body needs to be reflexively acknowledged by the researcher. She points out that embodied reflexivity offers opportunities for the researcher, both through its methodological implications and by providing additional rich material for analysis.

Finlay (2008) advocates attending to the body during the research process through three interrelated approaches, namely bodily empathy, embodied self-awareness and embodied inter-subjectivity. Bodily empathy involves the researcher's focus on bodily gestures. Following Merleau-Ponty, she notes that the researcher can identify with the participants' gestures to achieve a deeper sense of understanding. An extract from Finlay's interview with Ann, a woman struggling with multiple sclerosis, illuminates her argument:

She described the sense of almost panic which hit her when she suddenly realized she may not ever again be able to feel the softness of her baby's skin properly. She gently caressed her own cheek and then reached out to caress the child imagined in front of her. She described this as doing the "mummy think." Those fleeting, imaginary, subtle caresses disclosed a profound understanding. Suddenly, I understood that I needed to tune in her bodily experience especially her experience of being unable to connect with - being unable to love - her children. Without sensation she loses her ability to caress and hold and to express the love of her children. ....Seeing Ann's subtle gestures allowed me to listen and understand better. Because I was able to relate to the gesture, I could understand her experience. (Finlay, 2008, p. 23)

The second approach, embodied self-awareness, involves probing our own embodiment as researchers. This means that the researcher should reflect on how she herself is being affected at a bodily level (Finlay, 2008, p. 24). Such an approach can trigger unexpected feelings and responses; it can also provide new insight into something about herself that the researcher has little knowledge of. In this context, 
Finlay describes experiencing various bodily reactions while reading through the transcripts from her interview with "Jenny," a therapist who had been seriously threatened by a male patient. She then elaborates on how these bodily reactions influenced her analytical focus:

The sensations in the pit in my stomach, the hollow beating of my heart, my creeping skin. I became aware that I was experiencing these embodied reactions. The power of these unexpected sensations pushed me further in the analysis. I could somehow "feel" I was onto something important. (Finlay, 2008, p. 25) Including the researcher's embodied experiences carries some risks. It may, for example, privilege the researcher's experiences at the expense of hearing the patient's experiences. Finlay therefore advocates a third approach, which she terms embodied inter-subjectivity. As she defines it, embodied subjectivity means paying attention to the bodies of both researcher and participant as they share an inter-subjective space. Once again invoking the thinking of Merleau-Ponty, she reminds us that communication comes about through the "reciprocity of my intentions and the gestures of others." It is as if the other person's intentions "inhabited my body and mine his" (Finlay, 2008, p. 26). These arguments raise the question of whether or not the researcher's bodily expressions and intentions can be separated from the participant's bodily expressions and intentions. We will pursue this question in our discussion of the next article.

\section{To Whom Does an Experience Belong?}

The third paper we will discuss is entitled "Frustrating disability: The lived experience of coping with the rehabilitation phase following flexor tendon surgery." In this article, which is based on an empirical study, Fitzpatrick and Finlay (2008) elaborate on their complementary roles in the research process. In the methods section, they emphasize that Fitzpatrick conducted all of the interviews and that his background as an occupational therapist, coupled with his novice skills as a researcher (he was a $\mathrm{PhD}$ student at the time) influenced his interview process as well as his interpretations:

I believe my occupational therapy background enabled me to engage the participants effectively in their interviews. I feel my training and experience allowed me a good insight into the patients' experience. I didn't expect to be surprised at the results, but I was. On reflection I quickly learned that I was initially approaching this study from my own perspective, expecting the patients' views to confirm my own assumptions. This study allowed me to begin to change my stance by trying to gain a sense of the meaning of injury from a patient's own perspective and not from my own. I wanted to be as critical as possible when reflecting upon each individual description. I tried to ensure a deeper insight into each description and attempted to put myself into their world and try to gain their meaning from it. (Fitzpatrick \& Finlay, 2008, p. 151)

In this extract, the reader gets a vivid sense of the effort Fitzpatrick made to focus on the participants' experiences and give less weight to his own presuppositions. Later in the article, he reflects candidly on the challenges this presents, emphasizing that he needed help from his co-author to understand the participants' struggles. His co-author, in contrast, had experienced living with chronic pain herself. Their divergent 
experiences complemented each other in the analysis of the findings:

Inevitably, my own experience and empathy influenced and possibly even inspired my analysis. While Niall was inclined to gloss over the impact of the pain his patients experienced, I saw it in their every movement and through their rehabilitation. But was I seeing my own pain? I had to remind myself continually to keep focused on the participants' experiences and stories, not mine. Niall had an important role to play here in monitoring this. (Fitzpatrick \& Finlay, 2008, p.151)

These reflections on the part of the researchers highlight how their bodily reactions, as well as their previous experiences, intertwined during their analytical process. Having experienced chronic pain, Finlay found herself reminded of her own sufferings during the interview process. To maintain some distance, she found it useful to discuss various interpretations of the patients' accounts of their pain problems with her co-author. In making the sources of their reflections on these matters explicit, Finlay and Fitzpatrick show how inter-subjectivity in phenomenological studies can be transformed from a problem into an asset.

In terms of reflexivity, this paper indicates that using one's own experiences of living with chronic pain can become a valuable qualification in the analytic process. Identifying with participants' experiences is, however, also a topic that is worth considering as an issue that could be a source of ambivalence in the research process.

\section{Ambivalent Feelings on the Part of the Researcher}

Involving one's own subjectivity can also create challenges by generating ambivalent feelings in the researcher. Grimbø's article dealing with "cancer patients' experiences of using an interactive health communication application" vividly illustrates this issue. Grimsbø conducted all the interviews in the homes of the participants, most of whom were seriously ill with metastases (Grimsbø et al., 2012). As a former nurse working with cancer patients, Grimsbø's nursing competence initially seemed to overshadow her research goals. On entering patients' homes, she could not help being involved in their situation. During the interviews, she often felt the need to offer comfort and support, allowing that impulse to take precedence over the questions that she had prepared. She described how in these situations she had been taught concerning restraining or bracketing her pre-understandings faded into the background, while her previous experiences as a nurse became a valuable source of information that influenced her interpretations. In the following passage, she reflects on these matters explicitly:

Other patients were severely ill; one of them could not even get up from the sofa, immobilized by respiratory problems. In this situation, the respiratory problems could affect the first author's own breathing, something which indicated the strong intertwinedness between these bodily conditions. Her experience as a nurse came back to her and she felt compassion and a strong desire to help, to show care and empathy. (Grimsbø et al., 2012, p. 4)

As revealed through reflections, the findings were also shaped by her interpretation of bodily gestures and symptoms during the interview process. Her 
discussion of how her own breathing pattern became intertwined with the patients' breathing problems gives the reader a stronger sense of how the data material was created and negotiated. However, Grimsbø does not elaborate on how her research questions were influenced by these bodily encounters. Did her empathic attitude towards the participants in greatest distress and suffering the most pain precipitate novel topics during the interview process? How did her empathic response affect her followup questions? Nevertheless, the relevance of Grimsbø's findings to her analytical process becomes evident in her use of logbooks. After each interview, she wrote a context description of her immediate impressions. In these entries, she reflected on the context of the interview and her own experiences before, during and after it took place. According to Grimsbø, her logbook served as a "reminder patch" of the atmosphere of the interview, helping her to "rebuild" the interview situation during the later analytical process (Grimsbø et al., 2012, p. 6). In the subsequent discussions with her co-authors, these logbooks proved immensely valuable in revealing her own bodily reactions during the interviews.

We will conclude this section with an article that explicitly elaborates on how the researcher's own bodily experiences become a challenge that needs to be taken seriously.

\section{To Lose One's Safety as Researcher}

In her article entitled "The lived body as experience and perspective:

Methodological challenges," Engelsrud explores some of the challenges that can arise if the researcher allows the participant access to the research material (Engelsrud, 2005). This article is based on her research on female aerobics instructors. Her objective is to visualize how the researcher's body creates access to, and comprises a limit to, the knowledge that is produced during the interview process.

Engelsrud uses her relationship with Edith, one of the participants, to illuminate this theme. At the time, Edith was in her mid-30s and, according to Engelsrud, a "popular" instructor at the fitness center. In their informal conversations with Engelsrud, customers described her as an "excellent" and "secure" instructor (Engelsrud, 2005, p. 271). A radically different portrait emerged during the interview process with Edith. She spoke at length about her ambivalence towards training and fitness, as this excerpt from the article illustrates:

When Edith repeated that she was 'sick, sick, sick," I experienced her intonation immediately as resigned and that she sort of vanished from her face. The intonation and the way she repeated "sick, sick, sick" made an impression on me. It was as if time had stopped for a moment. I felt my heart rate increase and I began to perspire. The bodily expression of my awareness of what was taking place between Edith and me was no longer that of calm breathing and a relaxed body. I became warm, alert and full of inner agitation. ..... From our starting out in a relaxed atmosphere with coffee and pleasant conversation, the interview had suddenly moved into uncertain waters. The intonation, tension in the voice, the downcast eyes and the hunched over body, created a strong contrast to how I had experienced Edith when she was teaching and in the training studio in front of all the customers. (Engelsrud, 2005, p. 272) 
As indicated in this passage, the researcher's bodily reactions made her vulnerable, challenging her communication with the interviewee. She felt safer keeping quiet and letting Edith do the talking. The text vividly reminds the reader of how the researcher's own body sets a limit to what she can ask her participant. At this point in the interview, there is little reflexivity between Engelsrud and Edith. The researcher is guided by her own embarrassment when reflecting on what might be at stake for Edith. She uses her own bodily sensations as a means of interpreting Edith's feelings concerning the situation without actually "knowing" how Edith regards the interview situation and without her being compelled to talk about sensitive and seemingly vulnerable topics. We are told, however, that Edith herself changed the subject, which could indicate that she found the situation uncomfortable. Engelsrud, on the other hand, interprets Edith's sudden change of subject as a means of extricating herself from a situation of vulnerability.

In this article, reflexivity is initiated when Edith is invited to read through the interview. The researcher's intentions were to establish communication and acquire further insight into her thinking through her comments. However, Edith's immediate response to the written transcript was one of anger, sadness and mistrust. After reading only the first part of the text, she confronted the researcher in the locker room at the fitness center and challenged what she claimed was a distorted version of the thoughts she had expressed during the interview, "With tears in her eyes she handed me the pages of the interview transcript and said in a tearful voice: This is not what I want, there are all kinds of mistakes here, I sound like...like... She stopped mid-sentence" (Engelsrud, 2005, p. 274).

Later in the evening Edith apologized for her initial reaction and asked to read the rest of the interview. In her response, the researcher expressed her own apologies for having contributed to Edith's discomfort. However, instead of encouraging Edith to explain what she had experienced, the researcher chose to block out what she herself had experienced as a vulnerable situation. Hence, once again, we are vividly reminded of how the researcher's vulnerability limits the topics she is able to address.

Engelsrud asserts that her bodily reactions were first and foremost engendered by fear that Edith would withdraw from the project: "I was afraid she would once again say 'that's enough' (Engelsrud, 2005, p. 276). In this instance, Engelsrud illuminates how taking care of participants' own self-understanding is important in a research process, and makes the argument that researchers need to be aware that participants are vulnerable and want to be treated with respect.

\section{Further Discussion}

\section{The Relevance of Bodily Embarrassment and Shame as Productive Guidelines for the Novice Researcher}

As highlighted in the presentation of all five articles, researchers' critical reflections are relevant during the interview situation as well as in determining the findings. By critically engaging the researchers' own subjectivity, we will argue that these articles provide insights relevant to the phenomena being examined. Recognizing 
this, we will elaborate further on the experiences of the first author (Groven) in being a noise researcher. In particular, we will highlight how she increasingly learned to inform her reactions and questions with ongoing reflections throughout her $\mathrm{PhD}$ project.

The first author's PhD project deals with the life situation of morbidly obese women and how it changed following weight-loss surgery. We will elaborate further on reflexivity based on her project and discuss how it could be linked to the concepts of subjectivity and inter-subjectivity.

As part of her interview process, Groven wrote notes and comments in the margin when episodes or specific phrases struck her in a distinctive fashion. Her initial reflections were retrospective, derived from episodes and phrases in interviews that had typically occurred several days earlier. In contrast, reflexivity as an immediate bodily response occurred during the entire research process, including the writing process. We will offer some examples.

During the interviews, a recurring theme revolved around the women's dramatic weight loss. As the women became slimmer, the shape and contours of their body changed and their skin became progressively looser. As this became more visible and noticeable, the women felt less and less comfortable and attractive. They complained of bad-smelling folds of skin that wobbled, sweated and chafed at the smallest movement; aprons of fat hanging in front of their stomachs; batwing arms; thick flabby thighs; and sagging breasts, all of which were a dramatic contrast to the positive response they received to their changed body shape when they were out and about with their clothes on. The first author interpreted the statements in the interviews as aversive feelings. To underscore these emotions, she observed, the women pulled up their blouse or sweater and pointed to the parts of their bodies where they considered the skin to be particularly problematic. These situations - often taking place in the middle of the interview - made her wonder whether the women felt embarrassed and perhaps even ashamed. Although neither the women nor the first author ever voiced such words, she felt embarrassed by her own aversive thoughts and feelings when she saw and perceived their bodies. At the same time, she felt ashamed of these feelings that she could not "move away from". Drawing on her clinical experience as a physiotherapist, she was gradually able to "hide" these subjective feelings evoked in the inter-subjective situation. Assuming this learned professional distance enabled her to tone down her negative thoughts and feelings so that the women's experiences could become her primary focus.

The first author's bodily reactions and feelings during the interview process were "reproduced" when she read the transcripts from these interviews. Sitting alone in front of the computer, she could easily visualize the women standing in front of her with their blouse pulled up, pointing at various parts of their body. In hindsight, one could say that reflecting on the inconvenience of "staring" at the women's skin - perceiving their facial expressions, their tone of voice and the aversive expressions they used about their own bodies - facilitated and enabled the first author in generating important knowledge. Having given birth to two children herself, she used her own "struggle" with excess skin on the stomach as a relevant reference. Perceiving the participants' skin made her realize that her own "problems" were minor compared to theirs. Once she developed this perspective, when the women emphasized their desire 
to remove the excess skin surgically, their personal experiences were immediately comprehensible to her. This enabled her to relate both to their subjective experiences of living with excess skin and their exposure of these experiences in an inter-subjective interview context.

\section{Further Discussion of Subjectivity and Inter-subjectivity in the Research Process}

As noted in our introduction, one of the methodological guidelines applied in qualitative research within the phenomenological tradition-particularly when the research approach is inspired by Husserl - emphasizes the significance of bracketing theoretical and practical pre-conceptions. This method is based on the idea that the researcher who follows it will attend more openly and objectively to the phenomenon under scrutiny (Finlay, 2008; Malterud, 2010; Dahlberg et al., 2008). However, as other researchers have noted, practicing bracketing is both challenging and somewhat contradictory, given the inter-subjective dimensions of human existence (Bengtsson, 2001; van Manen, 1997; Finlay, 2011). As van Manen argues, one problem phenomenological researchers have is that they often know too much about the research topic. Pre-understandings, coupled with existing bodies of scientific knowledge, influence researchers to start analyzing the phenomenon even before they come to grips with the significance of the phenomenological question (van Manen, 1997). Expanding on this concept, we pose the following question: How is bracketing put into practice by those advocating it as a basic premise for phenomenological research? And, does concern with bracketing reduce the meaning of using subjectivity and inter-subjectivity as basic ideas in the production as well as analysis of the research material?

Røseth and colleagues (2011) emphasize the significance of bracketing in their exploration of post-partum depression. They postulate that bracketing and withholding the existential claim help the researcher keep "an open mind" and "see the phenomenon in a fresh light," allowing it to "speak for itself" (Røseth et al., 2011, p. 2). This emphasis on letting depression "speak for itself" is particularly noteworthy given Røseth's clinical background as a psychologist. However, in her description of three interviews with "Nina," a former patient, Røseth does not offer any reflections on precisely how she managed to bracket her preconceptions. Husserl's writing regarding bracketing would suggest that the researcher undertake an extremely detailed and time-consuming effort to arrive at an unprejudiced description of the essence of the phenomenon (Dahlberg et al., 2008). The only reflections Røseth reveals concerning her own subjectivity are that the interviews were conducted in a "relaxed atmosphere" in "Nina's" home, and the "resulting descriptions" were "rich in meaning" (Røseth et al., 2011, p. 3). The paper does not elaborate on the researcher/participant relationship in this process, leaving us wondering how these rich meanings were generated. Did the researcher ask specific follow-up questions during the three interviews? If so, how were these follow-up questions shaped by her prior experiences as a psychologist? Did she put aside her clinical background, or did she use it as a means of establishing the "relaxed" atmosphere? Finally, how did she manage to establish a "relaxed atmosphere" during the interview process? We would argue that a researcher who emphasizes the use of bracketing should include explicit reflections on how she applied it during the 
research process. Failure to do so reduces the trustworthiness of the research.

According to Finlay, critics often misinterpret the notion of bracketing as an effort to be objective, open and unbiased. She argues that what the researcher really needs to do is retrain her preconceptions and focus more actively on the participants' views. Researchers, she argues, need to try "to be open to the other, to put aside our own and more general understandings of the world" (Finlay, 2008, p. 258). Given the inter-subjective dimensions of human existence, as emphasized in the work of MerleauPonty and Heidegger, one question becomes crucial: How can researchers practice openness and simultaneously put aside their general understanding of the world? What is it that is "put aside"? And how is openness achieved and lived? In her in-depth study of "Pat" - a woman undergoing cochlear implant surgery - Finlay tries to reconcile these approaches (Finlay \& Molano-Fisher, 2008). The following extract illustrates her attempt to suppress prior assumptions and limit prior understandings: "I had to work to put aside my assumption that improved hearing would be both inevitable and desirable. I also made a point of not engaging with the wider literature until after our own analysis was largely complete" (Finlay \& Molano-Fisher, 2008, p. 258).

In the same article, however, Finlay elaborates on her close friendship with the respondent in focus. We are told that they were friends and colleagues for many years before the study started. This information inevitably leads the reader to wonder how Finlay's previous experiences with this friendship might influence the questions she is asking, as well as her ongoing interpretation of her findings. Finlay argues that her close friendship with Pat was not a drawback in the study. While noting that her own pre-understandings inevitably shaped the subsequent interpretations, she dismisses the likelihood of bias by stating that "it is necessary to reflect on evolving understandings and to try to tease out [emphasis added] which perceptions belong to the researcher and which to the co-researcher" (Finlay \& Molano-Fisher, 2008, p. 259).

The term "tease out" indicates a belief that the pre-understandings of both researcher and co-researcher can somehow be pulled out of their bodies and distinguished from one another, as though they were concrete objects. But what kind of process is involved when experiences can be objectified? Since the article does not elaborate further on this assertion, we cannot be sure of the authors' position on this question. Their primary concern appears to be Finlay's roles as both interviewer and friend, and how the intertwining of these two roles enabled her to develop richer and more nuanced insight into the phenomenon of a cochlear implant. Consequently, the article provides little information about her co-author's background and role in the process, such as her pre-understandings and whether or not she tried to bracket them in the same manner as Finlay did. This omission leads readers to conclude that hidden and tacit knowledge colors the authors' analytical approach, and makes the role of the researchers' subjectivity unclear. They assert the need to "put aside their own understanding of the world" (Finlay \& Molano-Fisher, 2008, p. 258). Yet at the same time they argue that a researcher's pre-understandings will influence her subsequent interpretations. Once again, calling to mind the intertwined relationship between humans and the world, we ask: Wouldn't their findings have been more convincing if they had reflected more explicitly on their different roles and how their subjectivity was 
engaged in the interpretations that they reached in this collaborative study?

As noted in our review comments on the article entitled "The lived experience of coping with the rehabilitation phase following flexor tendon surgery," Fitzpatrick elaborates explicitly on his different roles in the research process. For example, he vividly reflects upon his background as an occupational therapist in discussing both the interview process and the findings that emerged as a consequence of the researcher/ participant relationship. In this regard, the researcher's professional background as a health worker is presented as an invaluable source of knowledge. However, Fitzpatrick does not explore whether or not this background created power-imbalance challenges in the interview situation. Moreover, the article does not consider the possibility that the participants left out taken-for-granted information due to the researcher's clinical background.

\section{First-hand Experience with Subjectivity and Inter-subjectivity}

In the first author's PhD project, her professional background as a physiotherapist turned out to be a two-sided coin. She felt impelled to deal with her own professional background in a cautious but strategic manner. Although she had extensive experience in speaking with patients who suffered from chronic pain and functional problems, she did not feel particularly competent in talking to patients about their eating disorders. This became especially noticeable when the conversation unexpectedly turned to experiences of illness in situations that involved food and eating. The women themselves termed such episodes "dumping" - a term which the first author was not familiar with at the outset of the study. In the interview situation she followed up dialogs concerning mood swings and shame associated with "dumping" as a means of getting a better sense of how the women themselves experienced and related to this phenomenon in their daily lives. Furthermore, when the women discussed "dumping" both as something unpredictable and as something they had learned to relate to, the first co-author asked them to describe these apparently contradictory experiences in further detail. To justify her insistent and inquisitive approach, she usually emphasized her lack of clinical experience with patients who had undergone weight-loss surgery. At the same time, she noted the research-related importance of bringing the patients' experience of this relatively "tacit" phenomenon to light. With the benefit of hindsight, we might say that minimizing her clinical competence - and adopting a "naïve" and inquisitive research approach - helped the researcher turn the participants into experts on the phenomenon of "dumping." Creating this inter-subjective context provided space for the women to contribute their subjective experiences to the interview.

When the conversation shifted to eating problems, however, the first co-author was more careful - perhaps even too careful - in asking follow-up questions. Although the women seemed to have a complex and somewhat problematic relationship with food, only five explicitly volunteered that they had experienced an eating problem or an eating disorder in the years prior to the surgery. Due to the tacit "nature" of this topic, the co-author decided not to pursue this question with the other women. She felt that it was too sensitive and further questions might provoke and offend the women. One could therefore argue that the first author's own subjectivity led her to avoid follow-up 
questions that she felt might jeopardize the atmosphere of trust that had developed in the interviews.

As Finlay points out in her article "Quoting the researcher," discussed earlier, an interviewer who adheres to such a careful and protective approach could "miss" some important findings. At the same time, these examples demonstrate how the researcher's own background had an ongoing impact on the reflections generated during the research process, as well as on her communicative approach during the interviews. As a result, the findings emerged out of the researcher-participant relationship through a process that could be described as dialogical, interactive and reflexive. By acknowledging both her own experiences and the interviewee's, it became impossible for the first author to bracket or to remain silent about her own background and pre-understandings. Instead, she decided to make them explicit, hoping this would make the findings more trustworthy.

However, as noted in Grimsbø's article, "Cancer patients' experiences of using an interactive health communication application," a researcher who engages her own subjectivity critically during the interview process is likely to experience ambivalent feelings that present her with various challenges, including ethical questions as to how personal and intimate questions can be. In addition, researchers who are clinical health workers can be tempted to offer support and guidance, allowing that impulse to take precedence over their role as researchers. We will argue, however, that these challenges should not be viewed as drawbacks, given their value in developing knowledge. Researchers' retrospective reflections on feelings and reactions they experience during interviews can produce new information that was not evident at the time. In our own research, we have both experienced ambivalent feelings about our backgrounds as professionally trained physiotherapists. For example, when conducting participant observation in various weight loss interventions we have felt provoked by the appearance and behavior of the physiotherapists in charge of the training sessions. Most are slim and fit. From their perspective, pushing participants to exercise harder seems both legitimate and necessary. However, when the participants are morbidly obese patients struggling with a variety of physical and emotional problems, even if the difference between being "slim and fit" and "obese and not-fit" remains unspoken, it is highly visible. The physiotherapists give little or no explicit attention to the patients' needs, and their difficulty in keeping up the pace. During the interview process, some of the participants complained to us that the physiotherapists had no idea of what exercise entailed for these women. As one participant expressed it, "How can these super-slim physiotherapists have any idea what we are going through?" Hearing how degrading participants found such experiences made the first author feel ashamed of being a physiotherapist. Even though these aspersions were not directed toward her personally, they inspired her to reflect upon the different and perhaps even contrasting experiences of patients and professionals in an inter-subjective situation. When the question of professional background came up in the interviews, the first author usually toned down her professional background, emphasizing instead her role as a $\mathrm{PhD}$ student eager to learn about the participants' experiences. She repeatedly stressed that she was not hired by the clinic, and did not know any of the physiotherapists personally. This 
was a strategic effort to subjectively position herself as someone on the patients' side; someone they could speak to as freely and critically as they wished.

In retrospect, we would argue that this approach enabled us to gain insight into the patients' relations to a professional, which was significant knowledge. Through her effort to become "one of them, and not one of the physiotherapists," we believe she obtained their candid views on the "strict" and "insensitive" physiotherapists, as opposed to those they considered kinder and more understanding. By taking part in informal small-talks in the wardrobe, the first author was able to obtain a more nuanced impression of variations among the physiotherapists than she could have gotten by simply observing and reflecting on her own role and reactions as a participant in the group activity. Moreover, her writings in a logbook after each session enabled us to reflect on these issues, including the roles that researchers take and are accorded. The logbook proved immensely valuable during our analytical process. We both read descriptions of some of the events out loud, including the first author's reflections on them. This procedure stimulated rewarding debate and influenced our subsequent findings.

It should be observed, however, that none of the participants were invited to read through the notes, which we regarded as strictly subjective documents that would serve exclusively as analytical tools in the research process. The recorded interviews were treated the same way; the women were never invited to comment on them. As Engelsrud discusses more fully in her article "The lived body as experience and perspective: Methodological challenges," if participants are permitted to read through findings, the researcher runs the risk of insulting them. The researcher/participant relationship could be altered in unforeseen ways; in the worst case, a participant might withdraw from the study, feeling misunderstood and "used" by a cynical researcher who distorts interactions to reach the results she was looking for.

In this context, we would agree that regarding interviews as purely subjective documents raises ethical issues that need to be addressed. When a researcher feels discomfort and tension during an interview, her bodily reaction might indicate she is about to breach an ethical line by pushing the participant too hard. Following Engelsrud's arguments regarding the sensitive and sensing body, the first author's bodily reactions usually served as a warning that an ethical line might be threatened. Feeling uncomfortable, particularly when sensing that the participant was having problems and unwilling to elaborate more on a topic, was considered a signal to change the subject and "give into" the present moment.

\section{Concluding Remarks}

As argued above, balancing the researcher's own subjectivity with the inter-subjective dimensions of the research process is challenging. Since meanings are negotiated between researcher and participant during the interview process, uncomfortable situations are likely to arise. Regardless of whether the researcher uses phenomenology or some other methodological approach, he or she needs to explore these issues. In this context, we recommend a reconsideration of the kind of work and "practice" essential to understanding the concept of bracketing in phenomenological 
studies. Methods developed by phenomenological researchers claiming to adhere to this concept in their empirical studies have not been convincing. As a result, subjectivity becomes a tacit and somewhat mysterious aspect of their reports on research. If researchers reflect explicitly on their own bodily subjectivity (and often vulnerable feelings) during the research process and they establish connections between the context of the interview, how the material is created socially and textually and how they utilize information from their own body when interpreting material, it is likely that they will be able to make their findings more inter-subjective and transparent -- and, in consequence, more trustworthy and valid.

Learning how to conduct phenomenological research may present a challenge to $\mathrm{PhD}$ students and other novice researchers in the process of developing their analytical skills. Although guidelines are available in the literature, each project is unique. Ultimately, the researcher needs to let her own bodily experience "count" when determining how to go about exploring the phenomenon in question. As our review of articles here indicates, reflexivity is considered a useful - perhaps even essential - approach in phenomenological research, potentially facilitating a deeper and more complex understanding of both the phenomenon under study and the research process itself. Drawing particularly on the first author's experiences of becoming a phenomenological researcher, we have provided an embodied view of how reflexivity can become a fruitful approach, even in situations that might initially seem challenging and uncomfortable. In this context, the use of personal reflections highlights the value of critically engaging - and making explicit - the researcher's own experiences during and after interviewing and/or observing respondents.

\section{Acknowledgements}

We would like to acknowledge Associate Professor Lisbeth Thoresen, University of Oslo, for providing useful comments on inter-subjectivity during the final revision of this article. We are also grateful to the Norwegian Fund for Post-Graduate Training in Physiotherapy for the financial support of our project.

\section{References}

Bengtsson, J. (2001). Sammanflätningar: Fenomenologi från Husserl to Merleau-Ponty. Uddevalla, Daidalos.

Bjorbækmo, W., \& Engelsrud, G. (2011). "My own way of moving" - Movement improvisation in children's rehabilitation. Phenomenology \& Practice, 5(1), 2747.

Cerbone, D. R. (2012). Methods in phenomenology after Husserl. In S. Luft \& S. Overgaard (Eds.), The Routledge companion to phenomenology. London: Routledge.

Dahlberg, K., Dahlberg, H., \& Nyström, M. (2008). Reflective lifeworld research. Hungary: Studentlitterature.

Dahlberg, H. (2011). Vikten av kropp. Frågan om kött och människa i Maurice Merleau-Pontys Le visible et L'invisible [The weight of the body: The question of flesh and human being in Maurice Merleau-Ponty's Le visible et l'invisible] 
(Doctoral dissertation). Department of Literature, History of Ideas and Religion, Gothenburg University, Gothenburg, Sweden.

Engelsrud, G. (2005). The lived body as experience and perspective: Methodological challenges. Qualitative Research, 5(3), 267-284.

Finlay, L., \& Molano-Fisher, P. (2008). Transforming self and world: A phenomenological study of changing lifeworld following a Cochlear implant. Medicine, Healthcare and Philosophy, 11, 255-267.

Fitzpatrick, N., \& Finlay, L. (2008). "Frustrating disability": The lived experience of coping with the rehabilitation phase following flexor tendon surgery. International Journal of Qualitative Studies on Health and Well-being, 3, 143154.

Finlay, L. (2008). The body's disclosure in phenomenological research. Qualitative Research in Psychology, 3(1), 19-31.

Finlay, L. (2011). Phenomenology for therapists: Researching the lived world. London: Wiley-Blackwell.

Finlay, L. (2009). Debating phenomenological research methods. Phenomenology \& Practice, 3(1), 6-25.

Finlay, L. (2002). Quoting the researcher: The provenance, process, and practice of reflexivity. Qualitative Health Research, 12(4), 531-545.

Grimsbø, G. H., Engelsrud, G., Ruland, C., \& Finset, A. (2012). Cancer patients' experiences of using an interactive health communication application. International Journal of Qualitative Studies on Health and Well-being, 7(2), 15511-1524.

Käll, L. (2006). Expressive selfhood (Doctoral dissertation). University of Copenhagen, Copenhagen.

Malterud, K. (2010). Qualitative methods in medical research. Oslo: Universitetsforlaget.

Merleau-Ponty, M. (2002). Phenomenology of perception. London and New York: Routhledge.

Neumann, C. B., Neumann, I. B. (2012). Forskeren i forskningsprosessen [The researcher in the research process]. Oslo, Norway: Cappelen Damm Akademisk.

Pezalla, A. E., Pettigrew, J., \& Miller-Day, M. (2012). Researching the researcher as instrument: An exercise in interviewer self-reflexivity. Qualitative Research, $12(2), 165-185$.

Røseth, I., Bongaardt, R., \& Binder, P-E. (2011). A case study of a mother's intertwining experiences with incest and postpartum depression. International Journal of Qualitative Studies of Health and Well-being, 6(3), 7244- 7253.

Starks, H., \& Trinidad, S. B. (2007). Choose your method: A comparison of phenomenology, discourse analysis, and grounded theory. Qualitative Health Research, 17(10), 1372-1380.

Todres, S. (2001). Body and world. Cambridge, Massachusets, and London: MIT Press. van Manen, M. (1997). Researching lived experience: Human science for an action sensitive pedagogy (2nd ed.). Ontario: Hignell Book Printing. 
Watt, D. (2007). On becoming a qualitative researcher: The value of reflexivity. The Qualitative Report, 12(1), 82-101.

Zahavi, D. (2001). Beyond empathy: Phenomenological approaches to intersubjectivity. Journal of Consciousness Studies, 8(5), 151-167. 